\title{
Reorienting Deliberation: Identity Politics in Multicultural Societies
}

\author{
REBECCA MASON \\ Department of Philosophy, Northwestern University, Evanston, Illinois, USA
}

\begin{abstract}
Many political theorists argue that cross-cultural communication within multicultural democracies is not best served by a commitment to identity politics. In response, I argue that identity politics only interfere with democratic participation according to an erroneous interpretation of the relationship between identity and reasoning. I argue that recognizing the importance of identity to the intelligibility of reasons offered in the context of civic deliberation is the first step towards the kind of dialogue that democratic participation requires.
\end{abstract}

\section{Introduction}

Democratic societies minimally require communication among citizens and between citizens and governments in order to develop and maintain the legal and political frameworks that are most likely to promote peace and justice. Given the importance of this kind of communication to democratic participation, it is necessary to ask the following question: What is most likely to facilitate communication within a multicultural civic public in which citizens do not necessarily share a cultural history let alone political values or ideals? Many political theorists have answered by arguing that cross-cultural communication is not best served by a commitment to identity politics. ${ }^{1}$ In this paper I respond to the objection that identity politics interfere with cross-cultural communication in democratic societies. In particular, I address an objection to identity politics raised by Jeremy Waldron (2000), who argues that members of minority groups make a mistake when they assert their identity as rights claims in the context of civic deliberation. Identity politics, on this account, obstruct civic deliberation by preventing citizens from entering the discursive space that cross-cultural communication requires.

In response to Waldron, I argue that identity politics only interfere with democratic participation according to an erroneous interpretation of the relationship between identity and reasoning. Drawing from the work of Linda Alcoff (2006), I argue that recognizing the importance of identity to the intelligibility of reasons offered in the

Correspondence Address: Rebecca Mason, Department of Philosophy, Kresge Hall 2-335, 1880 Campus Drive, Northwestern University, Evanston, IL 60208-2214, USA. Tel: +1 847 491-3656, Email: remason@u.northwestern.edu 
context of civic deliberation is the first step towards the kind of dialogue that democratic participation requires. Alcoff suggests that one's identity consists in one's positioning in what she calls a "horizon of intelligibility." According to Alcoff, a horizon of intelligibility is a "perspectival location from which the interpreter looks out at the world" (p. 95). According to this view, identities are interpretive locations that enable individuals to make comparative judgments about questions of central importance to their lives. I use Alcoff's conception of identity to respond to the objection that identity politics interfere with communication and therefore democratic participation. Identities, in Alcoff's account, frame our understanding of the world and how we are situated with respect to it and the other citizens with whom we share it, and should be seen as starting points for reasoning rather than endpoints that dictate belief. In other words, identities have an important epistemic role as locations "from which knowing and perceptive analysis take place" (p. 125). As such, identity can factor into civic deliberation without suspending debate. By taking up Alcoff in response to Waldron, I hope to demonstrate that objections to identity politics on the grounds that identity interferes with democratic deliberation depend on an unnecessarily problematic conception of identity politics as well as the role identity plays in reasoning.

Before going into the details of Waldron's objection to identity politics, and my response to it, I should make two things clear. First, I want to elaborate what I mean by "identity politics" - a term much used and abused in political and philosophical theorizing around issues of social justice. Identity politics have come to signify a collection of political activities and theoretical discourses organized around the experience of injustice of members of certain social groups. In academic as well as public discourses about social justice, identity politics are used to ground both claims for redistribution and for recognition. For the purposes of this paper, I employ Waldron's conception of identity politics as well as Alcoff's alternative to it. According to Waldron, identity politics are a political strategy whereby citizens call attention to their cultural identities as the basis for demands of rights owed to them in virtue of their cultural-group membership.

My critique of Waldron's view involves claiming that this understanding of identity politics fails to take notice of the nuanced and various ways in which cultural identities are stitched into the fabric of citizens' epistemic and political lives. I engage Alcoff to suggest that identity politics is better conceived as a particular orientation to democratic participation. According to this view, identity politics affirm and embrace the ways in which cultural identity participates in the practice of deliberative reasoning that is instantiated in civic participation. I argue that focusing on the role identity plays in reasoning helps us to think beyond the idea that identities are prima facie obstacles to communication. Getting the right conception of identity politics is of paramount importance to this debate. Insofar as democratic deliberation (as I discuss it here) is primarily concerned with establishing and evaluating the basic structure of society, and how it distributes benefits and burdens among citizens, our understanding of identity politics will bear directly on how we think social justice is best achieved. In fact, identity politics - when properly understood-are the sine qua non of social justice. According to the characterization of identity politics I endorse here, the welfare of citizens is best promoted when cultural identity is recognized as a standpoint from which citizens reason about the social, political, and economic 
institutions which shape the societies in which they live. Because Waldron is concerned to establish normative standards for civic deliberation that best promote social justice, Alcoff's conception of identity politics is germane to the overall goal of his project.

The second thing I wish to clarify before I say more about my objection to Waldron's view is my reason for thinking that Waldron's account in particular merits attention in the first place. I have chosen to single out Waldron's view for two reasons. The contemporary aversion to identity politics has been expressed in a variety of ways; however, in comparison to many of his contemporaries, Waldron's critique is quite moderate. Not only does he take cultural identification seriously by arguing that culture is deeply connected to the ways in which people engage in political life (Waldron, 2000), he makes an honest attempt to accommodate cultural difference. His view can be contrasted with that of Arthur Schlesinger (1992), an influential critic of identity politics, who argues that the current "obsession with difference," threatens the possibility of a well-ordered society in which individuals are bound together by a common identity and a shared purpose. "The multiethnic dogma," Schlesinger says, "abandons historic purposes, replacing assimilation by fragmentation, integration by separatism” (pp. 16-17). He continues by claiming that separatism "nourishes prejudices, magnifies differences, and stirs antagonisms" (p. 17). Likewise, Jean Bethke Elshtain (1993) claims that identity politics ultimately collapse into contradiction because, according to her description, they advocate the exclusivity of group identities like ethnicity, gender, and sexual orientation, achieving inter-group diversity only at the expense of intra-group diversity. She argues that identity politics are "anathema to democratic thinking" (p. 38) because they encourage individuals to be more concerned with group-related grievances than with engaging in political life under the banner of the identity they share with others as free citizens. Elshtain says in no uncertain terms, "To the extent that citizens begin to retribalize into ethnic or other 'fixed-identity groups,' democracy falters. Any possibility for human dialogue, for democratic communication and commonality, vanishes as so much froth on the polluted sea of phony equality" (p. 75). Because Waldron's view represents a moderate position in contrast to the extreme views of theorists like Schlesinger and Elshtain, I think it is worth looking at his view more carefully. This paper engages Waldron on the very notion of reasonableness that his work both expresses and defends.

Furthermore, Waldron's critique stands out because of his choice to situate the politics of identity within the framework of human rights. I think this is a logical place to start the discussion given the important role rights have historically played in protecting individuals and groups from various forms of discrimination and coercion. The choice is also descriptively accurate: indeed, many contemporary identity claims are voiced in the language of rights. ${ }^{2}$ Although I ultimately reject Waldron's rights-based interpretation of identity politics, I think it is important to bring the politics of identity into conversation with "the moral and political language of the communities in which we live” (Brennan, 1999, p. 260). The language of rights continues to be the language in which most claims to social justice are voiced; as such, it is an appropriate starting point for a discussion of identity politics. 


\section{Cultural Identity and Human Rights}

Governments throughout history have responded to cultural diversity with devastating brutality, inflicting a variety of abuses on ethnic minorities including but not limited to genocide, expulsion, coercive assimilation, and segregation. The popularity of the concept of "universal human rights" after World War II ushered in a new political era and with it a new set of policies to protect cultural minorities from the crimes of past centuries (Kymlicka, 1995). Liberals embraced the idea of universal human rights and the protections those rights afforded members of minority groups. Human rights help to ensure that "the members of ethnic and national groups are protected against discrimination and prejudice, and [that] they are free to try to maintain whatever part of their ethnic heritage or identity they wish, consistent with the rights of others” (Kymlicka, 1995, pp. 3-4). Given this history, it is not surprising that Waldron situates the politics of identity within a framework of rights. But the conflict between identity politics and democratic deliberation on his account arises primarily because of this association between culture and rights. Waldron argues that when individuals assert their identities as a matter of human rights, they fail to live up to their duty of civic deliberation.

In response, I argue that the framework of human rights is ill-equipped to accommodate some of the social and political challenges that arise in modern multicultural societies, in particular, those challenges posed by identity politics. ${ }^{3} \mathrm{My}$ point is not to refute Waldron's analysis entirely; indeed, I agree with Waldron insofar as I believe that the connection between human rights and identity politics may be ill-suited to the task of promoting cross-cultural communication. However, Waldron fails to consider that there are other ways to conceive of identity politics and understand how identity might factor positively into civic deliberation. Waldron's rights-based critique of the politics of identity derives from a misunderstanding of the nature of identity and how it functions in the conversational spaces of liberal-democratic, multicultural societies. I argue that Waldon imposes constraints on multicultural dialogue that actually undermine the possibility of a rich, cross-cultural conversation that is likely to (1) promote justice and human flourishing, and (2) facilitate understanding among differently positioned citizens in multicultural societies. Because Waldron's account of civic participation is intended to ensure the realization of these values, the core commitments of his account demand that he revise his understanding of the role identity plays in democratic deliberation. On closer examination, I argue, Waldron's rejection of rights-based identity claims does not preclude a revised conception of identity politics which aligns with his commitment to the ideals of democratic participation.

Most countries in the world today are multicultural. That is to say, states rule over people from a variety of different ethnic and cultural backgrounds. But the brute fact of geographical proximity is no guarantee that agreement on concerns relevant to the governance of a country can be taken for granted. Given this reality, Waldron argues that individuals have a duty to deliberate responsibly among themselves about the basic structure of society. Waldron claims that the duty of civic participation is a duty to come to terms with others who have disparate views and beliefs about societal relations and organization in order to maintain peace and promote justice and human flourishing. This duty requires that citizens engage with each other in a 
manner that is careful, responsible, and attentive to difference. Waldron explains that the duty of civic participation has two aspects:

It means (1) participating in a way that does not improperly diminish the prospects for peace or the prospects that the inhabitants will in fact come to terms and set up necessary [social, legal, and political] frameworks. And it means (2) participating in a way that pays proper attention to the interests, wishes, and opinions of all the inhabitants of the country. (2000, p. 155)

Waldron's duty of civic participation is designed to promote and protect communication among citizens and between citizens and governments. But identity politics, Waldron argues, is in conflict with the first aspect of civic participation outlined above. A commitment to the politics of identity improperly diminishes the chances that citizens will come to terms with one another's cultures and values in order to set up the social, legal and political frameworks necessary for a peaceful and just society in which all citizens can flourish. Proper attention "to the interests, wishes, and opinions of all the inhabitants of the country" does not involve treating cultural identity as a non-negotiable right.

Waldron (2000) maintains that cultural identity is serious politics. ${ }^{4}$ He points out that it is "played out for high stakes and with serious ramifications not only for who ends up with what, but also for the terms on which the basic social settlement is framed” (p. 158). Society's basic structure has such a profound influence on the lives of its citizens that the social, political, and economic institutions that comprise it demand justification. In Waldron's view, however, individual rights claims are not necessary or sufficient for a state to sanction the norms or practices of a particular culture. In fact, he argues that if cultural identity is asserted as a right, it will "undermine or preclude altogether the fundamental settlement which is the goal of civic participation” (2000, p. 156). In what follows, I explain how Waldron reaches this conclusion and provide a way to meet the objection he raises.

Identity politics, according to Waldron, pose a serious problem in circumstances in which various cultures propose different solutions to questions central to the governance of society. Identity claims of the sort Waldron discusses are usually made in the politics of a larger multicultural society; the larger society also has its own solutions to problems, and some of those solutions will contradict solutions posed by other cultures. Some solutions are "rivals" in that "they constitute alternative and competing answers to what is basically the same question" (Waldron, 2000, p. 161). If members of various cultures within one multicultural society assert their identification with the practices of their respective cultures as a rights claim, that is, as both inviolable and non-negotiable, resolution will be unattainable because not all cultures are "compossible." Waldron uses the concept of "compossibility" to understand the relationship between two contrary cultural practices, particularly in circumstances when it is difficult or impossible to accommodate both cultural practices within the same society. Waldron draws on what he admits is a "crude" example to illustrate his point:

In response to the enduring question of what rules are to be set up to govern the organization of families and households, culture A may answer "Polygyny," culture B may answer "Polyandry," and culture C may 
answer "Monogamy." If the larger society S (which includes individuals who self-identify as As, Bs and Cs) opts for monogamy, then clearly it is opting for an answer which directly contradicts the answer given in A (not to mention the answer given in B). (Waldron, 2000, p. 161)

These solutions, Waldron argues, are rivals in that they provide different and competing answers to the same question: How should families and households be organized? Although most cases in which identities are asserted as rights are not this straightforward, Waldron uses this simplified and rather unnuanced example to illustrate a situation in which there is some degree of opposition between different ways of life. All three solutions cannot possibly be accommodated in the larger multicultural society because members of each culture $A, B$, and $C$ think that the solution posed by the other cultures is mistaken or repugnant. In other words, they are not merely different, they are contrary.

The liberal enterprise, Waldron explains, relies on the premise that rights claims are not contrary in the way I've just described. "If I claim non-negotiably that some interest of mine simply has to be respected, my claim is thrown in question-not refuted necessarily, but thrown in question-by showing that it could not possibly be accommodated in a political union along with the similar claims of other people" (Waldron, 2000, p. 159). Waldron argues that when identity claims are presented as rights, in circumstances where the cultural practices in question are not merely different, but contrary, no society can accommodate the identity claims of all citizens. ${ }^{6}$ Therefore, according to Waldron, the legitimacy of identity claims in liberal democratic societies is prima facie dubious. Notwithstanding the democratic challenge posed by identity politics, Waldron points out that it may nonetheless be the case that it is neither possible nor reasonable for individuals to give up identity claims of this sort notwithstanding their contrariety. "Identity should not be expanded to cover every demand that a person makes, every opinion he had, every preference he wants fulfilled” (2000, p. 168). However, Waldron admits that neither can identity claims be shrunk, simply to dissolve the political difficulties contrary claims create.

Waldron argues that although, when possible, identity claims ought to be accommodated, he nonetheless maintains that identity politics "not only exaggerate but distort the way in which a person relates to the culture which is part of his identity" (2000, p. 168). He implores us to think about individuals' involvement in a culture in a non-multicultural setting and claims that "in this setting it is doubtful whether thoughts about one's culture - how marvelous it is; how colourful and distinctive; how important it is to the identity of each of us-will loom very large in people's involvement in the life of their community” (2000, p. 169). Waldron suggests that the contemporary assertion of identity claims as rights often stems from a desire to conform to the norms of one's culture, full stop. But he demurs: "It seems very odd to regard the fact that this is 'our' norm - that this is what we Irishmen or we French or we Maori do-as part of the reason, if not the central reason, for having the norm and for sustaining it” (2000, p. 169). Waldron thinks identity claims are often asserted as rights in multicultural societies as a matter of unreflective allegiance, rather than on the grounds of reasons.

He argues that the role played by reasons and reasoning is vitally important to a proper understanding of culture and its function for individuals and societies. In the 
example above, cultures $\mathrm{A}, \mathrm{B}$, and $\mathrm{C}$, disagree in response to the question of what rules ought to be set up to govern the organization of families and households. Waldron argues that members of culture A ought not to recommend polygyny on the grounds that polygyny is just what As do. By the same token, cultures B and C ought not to recommend polyandry and monogamy respectively, on the grounds that polyandry and monogamy are just what Bs and Cs do. Rather, each culture is expected to offer a reason-grounded proposal as to why the wider society $\mathrm{S}$ ought to adopt polygyny, over polyandry or monogamy over polygyny. The debate might go as follows: Members of culture $\mathrm{C}$ claim that monogamy provides a more stable familial structure within which to rear children. Members of culture A reply that polygyny is actually the ideal form of family organization because multiple childrearing parents can provide mutual support for one another and care for the children in a way only two parents cannot. Members of culture C reply that polygyny degrades women by treating them like property. Members of culture B weigh-in claiming that polyandry cannot be said to oppress women, yet is still a form of polygamy. Cultures A and B discuss the benefits of a non-nuclear family. Civic deliberation thus proceeds by evaluating the reasons for proceeding one way rather than another. Waldron argues that it is only when members of cultures $\mathrm{A}, \mathrm{B}$, and $\mathrm{C}$ participate in democratic deliberation according to this model that they meet their duty of civic participation.

Waldron's understanding of culture is framed by his view of citizens' and governments' civic task as one of establishing norms and institutions that conduce to peace and flourishing. Various cultural norms should be understood as offering reason-grounded proposals for proceeding in one way rather than another, thus these norms should not be asserted non-negotiably. But it is important to understand that Waldron is not simply invoking the constraints of "public reason" in his positive account of civic deliberation. In Rawls' political liberalism, public reason is a concept that specifies the guidelines and principles that should structure political deliberation. Public reason is a regulatory concept that restricts the kinds of reasons permitted in the process of civic deliberation to only those that draw upon public values and public standards; that is, reasons that could be accepted by another citizen qua citizen (Rawls, 1997, p. 771). Many political philosophers argue that “deliberation needs to be disciplined by norms of 'public reason,' which will exclude, for example, appeals to religious revelation or whose contents or appeal are in some other peculiar sense private or limited” (Waldron, 2000, p. 160).

Waldron's position is unusual among many liberal theorists for rejecting the restrictions that public reason imposes on democratic deliberation. He argues: "It is a serious mistake to approach the problem of intercultural deliberation first with the idea of deliberative discipline and the exclusion of certain lines of argument on the basis of some Rawlsian idea of public reason" (Waldron, 2000, p. 163). While reasons and reasoning are important to Waldron's model of civic deliberation, in his view we have a responsibility to "converse with others on their own terms, as they attempt to converse with us on ours" whether their reasons are public or not (Waldron, 2000, p. 163). The duty of civic deliberation, he argues, does not require "the tendentious and usually one-sided discipline of 'public reason'” (Waldron, 2000, p. 164).

For Waldron, cultures are functionally significant. He argues that cultures ought not to be uncritically respected simply because they are connected to individuals or 
groups; instead, cultures ought to be evaluated according to the reasons for which their cultural norms were established. Waldron suggests that cultural norms are best understood as solutions to social questions, such as how to rear children. Different cultures have different answers to significant social questions of this kind. "A culture," according to Waldron, "is (something like) an enduring array of social practices, subsisting as a way of life for a whole people . . . It represents the heritage of a particular people's attempts to address and come to terms with the problems of social life" (Waldron, pp. 160-161). Cultures ought to be taken seriously and taking them seriously, according to Waldron, involves showing respect for the reasons behind cultural norms, not cultural norms simpliciter. Cultural identification does not entail unqualified respect for cultural practices: absolute respect ignores the important function these norms have for a culture and misunderstands the function that they should have as reason-grounded proposals within a multicultural civic public.

Waldron concludes that rights-based identity claims are not only impossible to accommodate in a civic union along with the analogous claims of other people. They are also unnecessary for members of minority groups to defend their cultural identities. Because it is both possible and reasonable to expect people to give up identity claims qua rights, we do not have an obligation to respect cultural norms qua individual rights.

Yet all Waldron's argument demonstrates is that thinking of identity operating as a "right" is the wrong way to think about identity politics. He argues that a rightsbased interpretation of cultural identity misunderstands the relationship between cultures and individuals. ${ }^{7}$ Rights, Waldron claims, deemphasize or conceal the vitally important role played by reasons and reasoning in the relationship between individuals and their cultures. I think that there is some truth to both of these claims and my response to Waldron does not aim to refute either entirely.

"Rights are more than moral concepts; they are also a practice," Samantha Brennan argues (1999, p. 269), and the practice of rights can go wrong in various ways. Waldron's argument helps to show that the association between identity politics and human rights is one of the ways in which the practice of rights can go wrong. Identity politics qua rights may interfere with our ability to discharge our duty of civic responsibility; however, this does not mean that identity politics are wholly pernicious. Waldron's thesis that identity, when asserted as a rights claim, interferes with cross-cultural communication may be correct, but this does not entail that identity plays only a debilitating role in the process of civic deliberation.

A rights-based interpretation of identity politics may obscure the relationship between cultures and individuals, but I think it also obscures the relationship between cultural identity and reasoning. Notwithstanding the political utility of rights-based identity claims, the language of rights does not provide an adequate framework for understanding the claims of modern identity politics. Instead, what is needed is a reimagining of how identity fits into the political and epistemic lives of individuals. A rights-based interpretation of identity politics may conceal the relationship between cultural identity and reasoning, but there are other ways of understanding cultural identity that do not conceal that relationship. Alcoff's account of cultural identity, to which I will turn below, provides just such an alternative understanding. 
In conclusion, Waldron maintains that modern identity politics characterizes respect for culture in terms of human rights, claiming that the inviolability of individuals entails that individuals have a right to their cultural identity. He says, "the strongest demand that is made by modern identity politics is that we should respect the distinctive dignity of the cultural or ethnic background that each individual has or claims as his own" (Waldron, 2000, p. 158). Waldron concedes that identity claims are often appropriate, last-resort strategies employed by minority groups in circumstances where their claims to social justice are simply ignored, but maintains that identity politics otherwise interfere with democratic participation. He argues that there is a conflict between the assumptions of identity politics and our duty of civic responsibility. Identity, when asserted as a rights claim, interferes with or prevents cross-cultural communication, which is the responsibility of all citizens to promote. He advocates the view that allegiance to the practices of one's culture ought to be held and presented as a matter of reasons, rather than identity. Only then can the presentation of one's cultural practices in the process of civic deliberation count as fulfilling one's duty of civic responsibility, that is, "one's duty as a citizen to participate responsibly in deliberation about policy and law" (Waldron, 2000, p. 174).

In response, I argue that the conflict between identity politics and civic deliberation that Waldron describes is specious; Waldron misinterprets the nature of identity and how it affects civic responsibility. Waldron's principal concern is that democratic participation will be undermined by the demands of identity politics; however, because he misinterprets how identity ascriptions affect our duty of civic participation, he gives up what would, differently interpreted, better serve the ideal of responsible citizenship to which his account of civic participation aspires. Thus Waldron's critique of identity politics undermines his stated goal: that citizens in multicultural societies will come to terms with one another in order to set up the social, legal, and political frameworks necessary for a peaceful and just society in which individuals can flourish. In the next section, I support this claim by defending an alternative conception of identity provided by Alcoff. I offer a reinterpretation of the relationship between identity and communication, in particular, the kind of crosscultural communication that characterizes democratic participation in multicultural societies.

\section{Identities as Horizons of Intelligibility}

Alcoff (2006) provides an account of identity that does not entail the negative interference with our duty of civic participation as Waldron describes it. When individuals from cultures $\mathrm{A}, \mathrm{B}$, or $\mathrm{C}$ make an identity claim, they are not being inauthentic, or opportunistic; neither do they blindly identify with a cultural norm devoid of its reasons. Their identification, according to Alcoff's view, consists in their positioning in a "horizon of intelligibility" — a perspectival location that frames their understanding of the world and how they are situated with respect to it and the other citizens with whom they share it. Alcoff builds on the concept of horizon used by Charles Taylor (1989). According to Taylor, "my identity is defined by the commitments and identification which provide the frame or horizon within which I can try to determine from case to case what is good, or valuable, or what ought to be 
done, or what I endorse or oppose” (1989, p. 27). He argues that living within substantive frameworks or horizons is constitutive of human agency: "Our identities define the space of qualitative distinction within which we live and choose" (Taylor, 1989, p. 30). In Sources of the Self Taylor advances an alternative picture of selfhood-one that contrasts sharply with the disengaged self of modernity. According to the modern ideal, individuals ought to achieve self-mastery through reason. When successful, this results in a self who is capable of not only objectifying the surrounding world but her emotions, inclinations, fears, and compulsions as well. Taylor argues that this picture of the self is deeply mistaken. When Taylor talks about identity, he is discussing it in the general sense of answering the question: How should we understand what selfhood amounts to?

Alcoff builds on Taylor's concept of the self as situated within a horizon which determines where one stands regarding questions of what is good, worthwhile, admirable, or of value and applies it to the contemporary debate about identity politics. In the context of my discussion of civic deliberation, the concept of a horizon represents a substantive perspective from which central life questions (as identified by Waldron) have significance and within which the cultural solutions to those questions are comprehensible. Understanding identity as a kind of orientation in a horizon of intelligibility explains how identity politics might factor into civic deliberation without suspending debate or representing inauthentic ways of engaging with a culture. ${ }^{8}$ In this view, identities operate as interpretive horizons that enable individuals to make comparative judgments about questions of central importance to their lives.

A non-cultural example may help to make things clearer. Say I identify as an environmentalist. As an environmentalist, (say) I believe that nature (plants, animals, ecosystems, etc.) is intrinsically valuable. My identity, as well as my substantive belief in the intrinsic value of the natural world, guides all sorts of other beliefs I have. For instance: I believe that finding and using renewable sources of energy is extremely important; I believe that humans have an obligation to protect endangered species; I believe that drilling for oil in Alaska is not the right response to the scarcity of fossil fuels; I believe that it's better to get a little bit sweaty riding my bike to work than to drive a car. Now, say I am engaged in a debate with one of my fellow citizens about how the government should use the revenue from a recent tax increase. One possible use for the tax dollars is a state-of-the-art, national recycling and composting program. Such a program would have the practical consequence of diverting sixty per cent of waste away from landfills. The importance of my identity to reasoning comes into sharp relief when one considers what it would mean for me to "set aside" my identity as an environmentalist in order to participate in civic debate over what to do with the tax revenue. How could I possibly do such a thing and still have any opinion at all on the matter?

I could not consider the advantages and disadvantages of the various programs the money could fund without having some kind of frame of reference-a horizon of intelligibility — that guides my reasoning on the issue. Alcoff argues:

It is possible to engage in some amount of self-reflection about one's framing assumptions . . . and to submit these assumptions to thoughtful examination, but the judging that is going on even in this process of examination requires the operation of qualitative discriminations, or in

Studies in Social Justice, Volume 4, Issue 1, 2010 
other words, a context within which the reasons one gives for one's conclusions will be intelligible as well as plausible. (2006, p. 54)

Participating in the debate over the tax increase just means bringing my identity (and the substantive beliefs it comprises) to bear on the issue. Without my identity my participation in the debate would be, quite literally, meaningless. ${ }^{9}$ This example helps to illustrate that when an individual draws attention to her social identity, she identifies herself as someone who is embedded in a particular frame of reference and whose particular value judgments inform her political perspective. ${ }^{10}$

According to the view of identity I am endorsing, identities are fundamental to reasoning and do not represent inauthentic ways of identifying a culture. Alcoff (2006) explains, "The horizon is just the individual or particular substantive perspective that each person has, that makes up who that person is, consisting of his or her background assumptions, form of life, and social location or position within the social structure or hierarchy" (p. 96). Alcoff's view shows how attention to identity is vital to the positive project of civic engagement that Waldron endorses. The remainder of this paper defends her insight that identity politics support rather than undermines the ideals of democratic participation Waldron recommends.

\section{Identities, Cross-Cultural Communication, and Civic Deliberation}

Before the development of the radio and telegraphs, when the primary method of communication over a distance (other than letter writing) was through smoke signals and beacons, the distance to the visible horizon represented the maximum range of communication and vision. As a consequence, “a horizon of" is usually used as a metaphor for the limit of perception, experience, or interest. According to the standard interpretation, a horizon could be used metaphorically to convey the limit of an available cultural viewpoint. But Alcoff uses the horizon metaphor in a nonstandard way to draw attention to both the limit of an available cultural viewpoint and the possibilities for understanding the horizon provides. As Alcoff uses it, the metaphor "a horizon of" takes on a kind of duality.

As the example of the environmentalist who is asked to participate in a debate without her identity demonstrates, understanding the issue at hand is impossible for her without her identity. She can't bring her opinions to bear on the discussion without some frame of reference within which she can make judgments about what is good, valuable, worthwhile, and so on. Thus a horizon of intelligibility opens up possibilities for understanding. Because each individual's identity is grounded in a horizon that sets the range and scope of communication possible from that location, a horizon also represents the maximum range of intelligibility that an individual's perspective affords. Thus a horizon of intelligibility limits possibilities for understanding.

My analysis embraces this duality, advocating a stance towards communication that does not understand horizons of intelligibility as fixed and unchangeable. Communication among individuals situated in different horizons is an imaginative exercise. It involves not simply evaluating the reasons behind a particular cultural norm; it involves imagining oneself as having a different set of substantive beliefs and value commitments. If citizens are unwilling to shift their location on the 
horizon with respect to other citizens with whom they are in conversation, the possibility for cross-cultural communication will be diminished by the limiting aspect of horizon. But discursive spaces can be adjusted to accommodate the various ranges of communication afforded by the various horizons of intelligibility that inform the reasons offered up in the process of civic deliberation. If another person's perspective is grounded in a location beyond one's horizon of intelligibility, the only way to make communication possible is to shorten that distance by one or both of the individuals reorienting themselves in the discursive space.

An example may help to make this point clearer. Alcoff imagines how most parents in the United States or Canada would react to the decision of one of their children to join a religious sect, like the Amish. The child could explain the reasons behind her decision in detail and with clarity to parents who listened carefully to her every word. ${ }^{11}$ Nonetheless, the parents would still fail to understand the child's decision unless their lives were such that they had previously held, or were open to holding, a particular set of values: "The value[s] of community and having a wellordered, morally and spiritually meaningful life over the value[s] of individual freedom, autonomy, integrity, or self-determination, and perhaps even over rationality itself” (Alcoff, 2006, p. 55). Parents' failure to understand such a decision would constitute a "gap of intelligibility between the reasons the child gives and what their parents can comprehend" (Alcoff, 2006, p. 54), and would point to a difference in substantive belief that cannot be bridged by examining the child's stated reasons for her choice. It is not simply the reasons the child articulates that are the source of the parents' failure to understand, but the substantive commitments that make those reasons intelligible. Before the child's choice could be understood as rational, the parents would not simply have to rigorously evaluate the child's reasons; rather, they would have to reorient themselves in qualitative space in such a way as to be open to an entirely different set of substantive commitments.

In contrast, Waldron sees interaction between cultures in terms of negotiation. In circumstances in which mutual accommodations are not available, what norms societies ought to follow must be decided through a process of civic deliberation, which involves examining the reasons behind cultural norms. Waldron suggests asking the following questions in order to assess the appropriateness of cultural norms in civic debate: Is the argument a good one? Are the facts right? Do the major premises of the argument point to values that are of real importance? Could the important values be secured by any other means? In response, I ask: What does it mean to ask oneself any of these questions in absence of one's cultural identity (recall the example of an environmentalist participating in a debate about the tax increase)? None of the questions that Waldron proposes to guide civic debate can be answered without qualitative judgments, according to which assessments of what is good, worthwhile, admirable, or of value are intelligible.

Waldron's model of civic deliberation relies heavily on participants' ability to evaluate the reasons behind various cultural norms. But, as Alcoff points out, evaluative judgments always make use of substantive commitments and qualitative distinctions. Her analysis draws attention to the "interpretive nature of identity" (2001, p. 63): 
To attain knowledge in most cases we must engage in a process of reasoning, and to engage in most kinds of reasoning - practical reasoning, moral reasoning - we must engage in a process of judgement . . . Judgment involves a qualitative weighing of the evidence; it is not simple deduction, but more akin to an interpretation. (Alcoff, 2006, p. 94)

This interpretive account of identity focuses on the epistemic role of identities as locations "from which knowing and perceptive analysis takes place" (Alcoff, 2006, p. 125). Accordingly, our duty of civic participation requires more than the articulation of the reasons behind cultural norms. As the example above demonstrates, it often requires an attempt to understand the substantive commitments that make up a person's cultural identity and render the world intelligible to her. Because identity is constitutive of how individuals come to understand the world and their place in it, our civic obligations extend beyond the articulation and examination of reasons. Our obligations extend to the identity or interpretive horizon in which reasons are situated. This involves a stance towards civic debate that acknowledges the cultural embeddedness of rationality and how that might affect the ways in which individuals from different cultural locations enter conversational spaces as reasoners.

Susan Babbitt provides an example that helps substantiate Alcoff's insight that, even when expressed in a process of civic deliberation, reasons may remain opaque across the cultural backgrounds of different individuals and groups (Alcoff, 2006). In "Freedom and Democracy in Cuba: A problem of understanding," Babbitt calls attention to the fact that the conditions for understanding the social and political norms in Cuba require more than the articulation of facts or evidence about the Cuban situation. She says that understanding requires "reference not just to a way of life, but more importantly . . . to an orientation toward that way of life" (1999, p. 87). Babbitt points out that despite the fact that there are 54 doctors per 10,000 citizens in Cuba (much higher than the respective proportion in the United States, even though the United States is much wealthier than Cuba), that all education is free to all Cubans, and that Cuba's constitution guarantees rights to work, health, education, and social assistance, Cuba is still criticized for failing to respect human rights. ${ }^{12}$ Babbitt argues that in the case of Cuba:

It is not enough to consider empirical evidence; it is also necessary to consider the conceptual and practical background which explains the importance given to the evidence. Moreover, one has to consider the fact that relevant philosophical assumptions are now very powerful, that they constitute the basis for a world view, informing the way people see themselves and interpret stories and experiences. (Babbitt, 1999, p. 83)

Babbitt explains that the fact that Cuba continues to come under criticism for failure to respect human rights is not because critics fail to consider the evidence. It is, instead, because they occupy a cultural-epistemic location such that they assign a lower level of importance (or no importance at all) to the evidence in questionevidence such as higher literacy rates and a better healthcare system in Cuba. Instead, a high level of importance is assigned to the fact that Cuba lacks a multiparty democratic system. Freedom to choose among a variety of political candidates, according to this point of view, trumps all other evidence offered for the belief that Cuba respects human rights. While all of the evidence presented is true, 
the respectively low and high levels of importance assigned to the evidence inform the belief that human rights in Cuba are not, in fact, respected. Conversely, those who believe that human rights in Cuba are, in fact, respected occupy a culturalepistemic location such that they attribute a low level of importance to a multiparty democratic system and a high level of importance to the other evidence.

Whether or not human rights in Cuba are, in fact, respected is not, however, my concern in this paper. What Babbitt's example helps to demonstrate is how, in Alcoff's vocabulary, horizons of intelligibility direct salience and importance, and influence value judgments such that the articulation of reasons and the evidence cited to substantiate those reasons is inadequate to support the kind of civic deliberation Waldron describes. The debate around whether or not Cuba respects human rights reaches a stalemate despite the fact that both sides articulate the reasons behind their respective beliefs because both sides attribute different levels of importance to the evidence. Understanding why one might believe that Cuba does respect human rights "requires not just truth, but the development of the conditions for ascribing importance to truths, for seeing how such truths matter or could matter" (Babbitt, 1999, p. 92). In the case of Cuba, understanding involves considering the substantive commitments and value judgments that explain why different levels of importance are assigned to the evidence. Similarly for the process of civic deliberation, the substantive commitments of both sides, the position each occupies on a horizon of intelligibility, the conditions for ascribing importance to truths, not just the reasons, must be considered. Each side must be open to holding a different set of values-of attributing a different level of importance to the evidence in question in order to evaluate those reasons. Babbitt's discussion of Cuba helps to illustrate Alcoff's point that while our ability to conduct conversations across conceptual schemes is not impossible, cultural identity is a condition of those conversations, by being a condition of the kind of reasoning we must deploy to participate in them.

Waldron argues that our first responsibility "is to make whatever effort we can to converse with others on their own terms, as they attempt to converse with us on ours, to see what we can understand of their reasons, and to present our reasons as well as we can to them" (Waldron, 2000, p. 163). Alcoff's analysis shows how cultural identity is vitally important to the intelligibility of reasons offered in the context of civic deliberation. In order to enable productive deliberation, individuals must not only recognize the important relationship between cultural identity and reasoning, they must be willing to reorient themselves towards different interpretive horizons; that is, in the context of civic deliberation they must be willing to engage with the cultural identities of their fellow citizens, as well as their reason-grounded proposals. Learning to understand the substantive commitments that guide reasons and value judgments across different horizons will increase the maximum range of intelligibility among diverse social locations, thus enabling the kind of productive multicultural dialogue Waldron hopes to achieve.

\section{Conclusion}

Understanding identity claims in terms of individual rights is but one way to understand the politics of identity and is neither necessary nor sufficient to facilitate 
dialogue and promote peace and justice in present-day multicultural societies. The framework of human rights has served many important political movements quite well, even while it stands in the way of others. Waldron insightfully moves beyond the constraints of Rawlsian public reason, but he fails to envision ways of understanding cultural identity outside of the human-rights framework that presents problems for his account of civic deliberation. Because the intelligibility of reasons depends on a framework of substantive commitments, cultural identity ought to be seen as an epistemic resource necessary for civic debate not as an impediment to it.

The interpretive analysis of identity proposed by Alcoff avoids the obstacles entailed by a rights-based account Waldron describes. Alcoff suggests that identity politics involve an orientation to political deliberation which pays heed to the reality that reasoning requires a deliberative orientation to get off the ground. Her analysis indicates that the gap between unintelligibility and intelligibility requires more than the articulation of reasons that Waldron's analysis recommends. It involves an imaginative participation in the debate; that is, a willingness to reorient oneself towards different cultural identities in the discursive space by imagining one's self as having a different set of substantive beliefs and value commitments. According to the alternative interpretation of identity that I have supported, responsible citizenship and social justice will involve civic deliberation in which the deliberative space is characterized by citizens whose perspectives are rightly informed by their cultural identities and in which they engage with the cultural identities that inform the reasons of their fellow citizens.

\section{Notes}

1 In Visible Identities: Race, Gender and the Self (2006), Linda Alcoff identifies three main political arguments behind the contemporary critique of identity: the separatism problem, the reification problem, and the reasoning problem. Her taxonomy helpfully maps the complicated terrain of the debate around identity politics in much more detail than I have space for in this paper.

2 For instance, in France there is a total ban on religious symbols and apparel in schools. In their objections to the law, many Muslims argue that the hijab is a cultural head covering traditionally worn by Muslim women. It is an important part of their cultural identity and therefore they have a right to wear it. The same claims are made by French Jews, Sikhs, and Christians regarding skull caps, turbans, and large crosses respectively.

3 This thesis is not tantamount to a rejection of rights tout court. As Brennan (1999) argues, it may be the case that our moral theories ought to include rights, but that rights alone aren't sufficient. For the purposes of this paper I wish to remain agnostic or at least ecumenical with respect to human rights.

4 Contrast this with Schlesinger's trivializing analysis: Schlesinger locates the impetus behind identity-based movements in "the need for ethnic cheerleading" (Schlesinger, 1992, p. 56). While disingenuously touting the importance of cultural pluralism, he decries what he describes as the self-esteem building function of identity politics. He argues, "low selfesteem is too deep a malady to be cured by hearing nice things about one's own ethnic past. History is not likely to succeed where psychiatry fails” (Schlesinger, 2000, p. 101).

5 "Compossibility" is a technical term Waldron traces back to Leibniz. Two things are compossible when they are possible together; conversely, two things are incompossible when the existence of one rules out the existence of the other. In ethics and politics, he says, the term compossibility takes on a slightly different meaning. There, it refers to joint practicability. It is in this sense that Waldron employs the term compossibility. For the purposes of this paper, the term "contrary" is less technical and cumbersome and will suffice to convey the appropriate meaning. 


\section{Rebecca Mason}

${ }^{6}$ Waldron argues that when claims made by cultural groups are not contrary to similar claims of other citizens in a multicultural society, those claims ought to be accommodated.

${ }^{7}$ It is also worth mentioning that Waldron does not fully credit the ways in which individuals are driven to make rights-based identity claims in liberal democratic societies. Given the significant influence of human rights considerations on the ways in which legal and political frameworks are currently set up in the societies Waldron considers, there are few other ways in which cultural minorities can voice these claims even when they are not acting "strategically." Because I want to step outside of the framework of human rights in my discussion of identity politics, however, I do not here consider this objection to Waldron in detail.

8 The argument that rights-based identity claims represent inauthentic ways of engaging with one's culture is the only argument Waldron makes which I find exaggerated and unreasonable. There are real problems with his view that identity claims are artificial. Unfortunately, there is no room in this paper for a full exposition of my objections to his claims about inauthenticity. The thesis I do advance in this paper neither stands nor falls with those objections.

9 Drawing from Taylor, one might describe giving up my identity as a kind of "identity crisis": "An acute form of disorientation, which people often express in terms of not knowing who they are, but which can also be seen as a radical uncertainly of where they stand. They lack a frame or horizon within which things can take on a stable significance, within which some life possibilities can be seen as good or meaningful, others as bad or trivial” (Taylor, 1992, pp. 27-28).

10 Note that my identity, while necessary for me to participate in the debate, need not dictate my belief in the debate over the tax increase or the recycling program. Of course I am going to be strongly disposed to using the tax revenue to fund a recycling program, but this does not preclude my revising my commitments (even my identity) if new and compelling evidence is brought to my attention over the course of the debate. Perhaps I live in a country without public heath care (something I knew before the debate began) and learn (in the course of the debate) that even with the tax hike, there is not enough money to both fund public health care and the recycling program. I am persuaded to give up my support for the recycling program and lobby to have the tax increase support health care instead. I decide to start a small composting program in my community; I write letters to companies whose products I use most often encouraging them to limit their packaging as much as possible. I increase my monthly donation to the World Wildlife Fund.

${ }^{11}$ We can imagine the child citing such reasons as: "With the state of the world as it is, I have come to believe this is what's best for me," or "This community gives my life purpose, it makes me feel grounded in a way I've never felt before."

${ }^{12}$ Babbitt also draws comparisons with other statistics in the United States. In the United States she cites the facts that " 59 per cent of those condemned to death are members of minority racial groups . . . that funding for prisons has increased 30 per cent in the past 10 years while funding for education has decreased by 18 per cent during the same period ... 60 percent of the children at age eight do not know how to read; that 54 per cent of the suicides of young people in developed countries take place in the United States; and that social assistance has been reduced by 60 per cent” (Babbitt, 1999, pp. 82-83).

\section{References}

Alcoff, L. M. (2001). On judging epistemic credibility: Is social identity relevant? In Sandra Morgen and Nancy Tuana (Eds.), Engendering rationalities (pp. 53-80). Albany, NY: State University of New York Press.

Alcoff, L. M. (2006). Visible identities: Race, gender, and the self. New York, NY: Oxford University Press.

Babbitt, S. (1999). Freedom and democracy in Cuba: A problem of understanding. In C. Koggel (Ed.), Moral issues in global perspective (pp. 82-95). Peterborough, ON: Broadview Press. 
Brennan, S. (1999). Reconciling feminist politics and feminist ethics on the issue of rights. Journal of Social Philosophy, 30(2), 260-275.

Elshtain, J. B. (1993). Democracy on trial. CBC Massey Lecture Series. Toronto, ON: House of Anansi Press Ltd.

Kymlicka, W. (1995). Multicultural citizenship: A liberal theory of minority rights. New York, NY: Oxford University Press Inc.

Rawls, J. (1997). The idea of public reason revisited. The University of Chicago Law Review, 64(3), 765807.

Schlesinger, A. M. (1992). The disuniting of America. New York, NY: W.W. Norton \& Company.

Taylor, C. (1989). Sources of the self: The making of modern identity. Cambridge, MA: Harvard University Press.

Waldron, J. (2000). Cultural identity and civic responsibility. In W. Kymlicka \& W. Norman (Eds.), Citizenship in diverse societies (pp. 155-174). Toronto, ON: Oxford University Press. 